\title{
Personality Factors, Academic Stress and Socio-economic Status as Factors in Suicide Ideation among Undergraduates of Ebonyi State University
}

\author{
Ronald C. N. Oginyi ${ }^{1}$, Ofoke S. Mbam ${ }^{1}$, Nwonyi Sampson ${ }^{1}$, Ekwo J. Chukwudi ${ }^{2} \&$ Martin O. E. Nwoba $^{3}$ \\ ${ }^{1}$ Department of Psychology and Sociological Studies, Ebonyi State University, Abakaliki, Nigeria \\ ${ }^{2}$ Department of Psychology, Enugu State University of Science and Technology, Enugu, Nigeria \\ ${ }^{3}$ Department of Public Administration, Ebonyi State University, Abakaliki, Nigeria \\ Correspondence: Ofoke S. Mbam, Department of Psychology and Sociological Studies, Ebonyi State University, \\ P.M.B 053 Abakaliki, Nigeria. Tel: 234-80-6504-9858. E-mail: sunnycool4real1977@gmail.com
}

Received: May 2, 2018 Accepted: July 12, $2018 \quad$ Online Published: August 31, 2018

doi:10.5539/ass.v14n9p25 URL: https://doi.org/10.5539/ass.v14n9p25

\begin{abstract}
The major purpose of this research was to investigate personality factors, academic stress and socio-economic status as factors in suicide ideation among undergraduates. The second purpose was to determine the extent to which personality factors, academic stress and socio-economic status could buffer the negative impacts of suicidal ideation. Cross sectional survey was used for the design of this study and hierarchical multiple regression was adopted for data analysis. Results showed that personality factors, academic stress and socio-economic status jointly and separately predicted suicidal ideation. The research findings implied that interventions strategies to improve social network and assessment of their personality factors may have positive outcome in reducing or preventing suicide ideation among undergraduates
\end{abstract}

Keywords: academic stress, personality factors, socio-economic status, suicide ideation, undergraduates

\section{Introduction}

Suicide ideation is a serious psychological, social and cultural, public health problem and currently creates a lot of psychological concern to people of diverse backgrounds across the globe (Brezo, Paris, \& Turecki, 2006b). Suicide is the most worrisome psychological problem that significantly increases or leads to death among undergraduates in Nigerian Universities. This might create a lot of public health concern in our universities, organizations, educational, public and private sectors. Suicide ideation is seen as a major psychological killer of humans. It was observed that humans do not easily admit to commit suicide, while some people tend to die by suicidal acts. It was commonly observed that only those who are diagnosed of anxiety, stress, depression and personality problems are liable to commit suicide. Hence, about $50 \%$ of human(s) who die of suicide acts are not clinically sampled individual(s) or having personality and stress disorder which might result to significant increase in risk of committing suicide among undergraduates of institutions of higher learning, youths, adolescents and young adults. Suicide ideation constitutes one aspect of suicidal behaviour and refers to the human thoughts that life is meaningless of living, as well as current plans and thereby engage in wishes and thoughts to commit suicide (Pienaar, Rothman, \& van der Vijver, 2007). Suicidal ideation is a thought process in which an individual thinks about suicide but does not intend or plan to commit suicide. It can also be defined as the thought, intent, plan and imagination of an individual concerning suicide. Suicidal ideation is categorized into suicide attempts and complete suicide. Suicidal ideation is a common phenomenon among all individuals irrespective of age, gender, ethnicity, race, academic attainment or even socio-economic status.

World Health Organization (WHO; 2004) report that about two million people worldwide die of suicide regularly, accounting for more deaths than homicide, accidents and war combined. WHO also estimated that current worldwide trends, for the year 2015 approximately 1.50 million of human will die from suicide and 20 to 30 times larger people will commit suicide, representing mean of one death in every 30s and one tendency every 2 to 3 seconds. Planas, Bennasar, Perez and Arroyo (2001) noted that suicidal ideation increases among undergraduates, young adults and more recently suicide ideation has been implicated as being most regular incidents of death among people under age of 30yrs (Fanous, Prescott, \& Kendler, 2004). These incidents call for 
psychological concern as suicide ideation has been implicated as being the first warning sign of the eventual engagement in more serious suicidal behaviour such as attempted and complete suicide (American Psychological Association, 2004). Most people think that suicidal ideation constitutes a large psychological problem that should be prevented. However, how does one prevent such a psychological problem when the meaning of the underlying etiology and prediction is still imperfect (Schlebusch, 1995), and when the variables leading to suicidal ideation such as personality factors, stress, socio-economic status, attempted or completed suicide are diverse and touch on every part of human life.

There is a general view that suicidal ideation among undergraduates may have a negative impact on emotional and physical ill health. Personality factors, academic stress and socio-economic status serve as impediments to the undergraduates. This study therefore investigated the relationship of personality factors, academic stress and socio-economic status as predictors of suicidal ideation among a previously uninvestigated sample of the population, Ebonyi State university undergraduates. The second objective was to determine the extent to which personality factors, academic stress and socio-economic status can buffer the negative impacts of suicidal ideation among undergraduates. Research on personality and suicidal ideation among undergraduates has implications for improving understanding of personality factors and suicidal ideation as well as for enhancing their academic performance and school life. Understanding social environment and personal attributes on suicidal ideation my hold benefits for institutions and undergraduates. Also, it will help human resource specialists and career counsellors forecast suicidal ideation as well as factors related to early manifestation of suicidal ideation. From such clues, appropriate intervention strategies that will mitigate suicidal ideation and enhance academic performance and psychological well-being could be established.

Pervin and John (1997) defined personality as characteristics of a person that account for his or her enduring emotional, cognitive, and behavioural patterns. These patterns have been referred to as individual differences. Personality traits, which have been largely derived from the attributes or words that people use to classify themselves or others, describe the dimensional characteristics or disposition of an individual (Howland \& Thase, 2005; McCrae \& Costa, 1999). Therefore, personality factors provide a dispositional description of a person's characteristics, language and framework to describe personality (Murphy \& Davidshofer, 2005). Personality refers to the personal characteristic patterns of behaviour, thoughts and feelings that form an individual distinctiveness. Costa and McCrea's OCEAN model (Costa \& McCrae, 1985) viewed personality factors into five groups which include; openness to experience, neuroticism, conscientiousness extraversion, and agreeableness. These groups are supported by personality psychologists (Larsen \& Buss, 2005) that the domain of personality can be characterized by these five factors or global domains (Murphy \& Davidshofer, 2005).

Neuroticism is described as (susceptibility to psychological distress, depression, emotional stability/psychological adjustment, unhappiness, fear of aggression, guilt, embarrassment and disgust, anxiety disorders and borderline hostility (Larsen \& Buss, 2005). Extraversion (this represents sociability, talkativeness, assertiveness, activeness, care for in other human(s) and environmental events for stimulation, and tend to create positive affect or mood, such as happiness, interest, enthusiasm, love, and optimism (Ryder et al., 2005). Also, extraversion are disposition towards positive emotion, sociability, friendliness, enjoy being around people, and are affectionate, tend to be talkative, assertive, and active, seek stimulation, excitement and the company of others, and generally experience positive affect. Introversion is the opposite of extroversion (they are reserved, tend to be quiet, and are preferably comfortable with being alone, shy, unhappy or pessimistic) (Larsen \& Buss, 2005). Openness to Experience (the proclivity towards fantasy, creative, feelings, thinking, ideas, and thoughts, tends to be curious about their inner experiences and external world as a consequence of their behaviour. They also tend to, consider unconventional thoughts and thinking as unprincipled, as they apply their evolving value systems conscientiously as a traditionalist could do. These individuals also tend to have a rich and complex emotional life. Conversely, human (s) who are low openness tend to prefer familiarity than novelty, also they are conventional in behaviour, conservative in their outlook, and experience emotions less intensely) (Larsen \& Buss, 2005).

The Agreeableness are inclination towards sympathy, trust, cooperation and altruism, cooperative, and willingness to help others and have in mind that others will be helpful in future. (Ryder et al., 2005). Conscientiousness is the tendency towards persevering and responsibility, the ability to plan, organize and carry out cognitive tasks, capability, self-orientation and competence, purposeful, strong-willed, motivated, well organized, and determined. Whereas individuals with low disposition on conscientiousness tend to be untrustworthy, careless, lazy, low goal driven, experience difficulty in planning, organizing and carrying out tasks, and are more hedonistic (Ryder et al., 2005).

Research on personality correlates of undergraduate's suicidal ideation indicates that neuroticism was associated 
with suicidal ideation (Ryder et al., 2005). Kerby (2003) found low conscientiousness, low extraversion and high neuroticism participants and predicted suicide ideation in both genders. Also, females and males did not differ in suicide ideation. Results also revealed that gender differences did not interact with personality in predicting suicide ideation. Similarly, Daniel, Meghan, William and Frederick (2012) in their study found that personality domain had opposite association with suicidal ideation, with the exception of neuroticism, which had a high association and were mostly insignificant to reasons for living. Also, Brezo, Turecki and Paris (2006) in their study revealed that neuroticism and extraversion were statistically significant related to suicide ideation among undergraduates. Results also showed increase in neuroticism on suicide acts, suicide intention, and complete suicidal ideation. Results further revealed that extraversion was negatively related to suicide ideation among undergraduate students.

Heisel, Beckman, Conner, Duberstein and Franus, (2006) reported that increased record of neuroticism and openness was related to suicidal ideation among older adults. In the same vein, Seyyed, Negar and Sajjad (2015) investigated the role of personality factors in the chemical suicidal ideation and found suicide tendency got significantly larger scores in neuroticism and also lower scores in openness, extroversion, conscientiousness and agreeableness compared to normal individuals. Results also revealed that there were interaction effects of group differences by gender revealed that male suicide tendency had always larger neuroticism levels openness and lower extraversion compared to the other gender difference. Singh and Joshi (2008) investigated the association between depression, life stress and personality factors on suicidal tendency among undergraduate students and found that suicidal acts was positively related to stressful life events, depression, and two domain of personality factors, that is, psychoticism and extraversion. Multiple regression statistics revealed that three factors of personality domains significantly predicted suicidal ideation. Other researchers that supported this view include (Chioqueta \& Stiles, 2005; McLean, Maxwell, Platt, Harris, \& Jepson, 2008)

Ifeagwazi (2016) defined academic stress as pervasive clinical phenomenon that has been linked to health and illness of persons. Wood, Wood and Boyd (2008) and Raulin, (2003) defined stress as the biological, psychological and physiological conditions that threaten or interfere with human system and alter some form of adaptation or adjustment of such human body system. The human emotional response to stress triggers the biological, psychological and physiological arousal of human system due to increased activity of the sympathetic nervous system (Ifeagwazi, Chukwuorji, \& Kalu, 2013). The most current definition of stress now emphasizes the relationship between the individual and the environment (Taylor, 2003). This reflects the interactional or transactional model of stress, which conceptualizes stress as a process that includes stressors (events that produce threats to a person's well-being and strains (the person's physiological and psychological responses to stressors). According to Alloy, Jacobson and Acocella (1999) cognitive theorists see stress as not a stimuli or response, but as an association between the stimulus and the human's appraisal or interpretational of it, a process that determines a human(s) responses. These stresses have consequences on undergraduate's physical, emotional and psychological well-being.

According to Ifeagwazi (2016), stress is not necessarily bad as some researchers assume, but there are always differences between stresses that are positive/ beneficial (eustress) and stress that are harmful /damaging (distress). From an adaptive point of view, moderate level of stress facilitates and motivates adaption. Humphrey, Yow, and Bowden, (2000) see stress as any factors or variables acting internally or externally, which make adaptation of humans to environment difficult and which induce increased effort on the part of the person(s) to maintain a state of equilibrium between himself and herself and the external environment. Stress is one of the psychological factors that induces suicidal ideation among undergraduate students and researchers have found that stressful life events are positively related to suicide acts and suicidal ideation (Gould, Greenberg, Velting \& Shaffer 2003). There are numerous risks and protective factors believed to be associated with suicide ideation, attempts, and completion: depression, ethnicity, family socioeconomic status, prior suicidal behavior, anxiety, hopelessness, substance use, family and relationships issues, aggressive/impulsive behaviors, physical and sexual abuse, stressful life events, impaired coping abilities, exposure to suicide, low self-esteem, homosexual or bisexual orientation, poor communication with family members, family discord, financial problems, personality, aggression, poor academic achievement and performance, and poor peer relationships (Salami, 2011; Dogra et al., 2008; Hintikka et al., 2009; Smith, Alloy, \& Abramson, 2006; Stephenson, Pena-Shaff, \& Quirk, 2006). Knowing that these predictive factors are associated with suicide ideation allows clinicians in both mental and physical health settings to identify people who are at a greater risk for suicide ideation, and thus, efforts can be made to prevent the suicide process from beginning or progressing beyond suicide ideation. One strong predictor of suicide ideation in young adults is academic stress which gives rise to risk factor for young adult suicide ideation, particularly for the college population, because college students are believed to have high levels of 
perceived life stress (Smith, Alloy, \& Abramson, 2006). A relationship has been established between stress and suicide ideation. (Joiner \& Rudd, 1995; Lipschitz, 1995; Chang, 2002) present findings that suggest life stress is associated with suicide ideation. Specifically, Dogra et al., (2008) have found that college students who experience suicide ideation have greater levels of life stress.

In addition, Stephenson, Pena-Shaff, \& Quirk, 2006) and Singh and Joshi (2008) have shown significant associations between stress and suicide ideation among college students, indicating that people with a high level of life stress may have a greater tendency to experience suicide ideation. Moreover, Singh and Joshi (2008) have revealed that stress is a strong predictor of suicide ideation among college students, using multiple regression analyses. Thus, it is reasonable to maintain that stress, measured in terms of a person's perceived stress, would predict suicide ideation. Research evidences have shown that, undergraduates experiencing more stress were likely to engage in suicidal ideation (Anastasiades, Kapoor, \& Wooten, 2016). Rosiek, Rosiek-Kryszewska, Leksowski and LeksowskiK, (2015) found that chronic stress has a stronger negative consequences on mental health and suicidal ideation among undergraduate students. Also, chronic stressful- life events and anxiety have a negative outcome on mental health and also confirm a relation to suicidal ideation among undergraduate students. Similarly, Johnson, Gooding, Wood, and Tarrier (2010) conducted a study in which 88 sampled undergraduate students comprising of 43 males and 45 females with age range of between 12 to 19 years and mean age of 14.23 years and found that self-appraisals moderated the relationship between undergraduate student's stressful life events and suicidality. For those recording moderate or high levels of significant self-appraisals, raised incidence of students's stressful life events did not lead to increases in suicidality. The results supported the schematic appraisals model of suicidal ideation framework, and suggest that significant self-appraisals may confer resilience to suicidal acts. One study in particular conducted by Wichianson, Bughi, Unger, Spruijt-Metz and Nguyen-Rodriguez, 2009) examined the relationship between life stress and perceived stress and suicide ideation. These researchers found that life stress and stress perceptions were significantly associated with thoughts of suicide; their research suggests that perceived stress is a risk factor for suicide ideation (Wichianson et al., 2009). Therefore, it seems that an individual's perceived level of stress is a predictor of suicide ideation.

Other researchers whose works are in line with this view include: (Wong, Stewart, Ho, Liu, Tein, Zhao, \& Sandler, 2005; Yoder, Whitbeck, Hoyt, \& LaFromboise, 2006; Rao \& Lam, 2005; Hiramura, Shono, Tanaka, Nagata, \& Kitamura, 2008; Brown, 2011). Another variable that has serious disposition to suicidal ideation is socio-economic status.

Socio-economic status refers to an individual's position within a hierarchical social structure, which is one of the significant determinants of health status. Socio-economic status distresses overall human functioning, including physical and mental health well-being. Low socio-economic status and its associates, such as lower educational achievement, poverty, and poor health status ultimately affect our nation at large. Socio-economic status is a dependable and reliable predictor of a vast array of outcomes across the human life, including psychological health, physical and mental well-being. Socio-economic status is important to all realms of social and developmental factors including our social, cognitive, emotional, physical and mental life of humans. Increasing socio-economic status is related to increasing levels of psychological well-being. Psychological well-being is in turn related to physical and mental health of an individual. Higher socio-economic groups are more satisfied with life and have fewer psycho-somatic symptoms.

In studying suicidal ideation among undergraduates, researchers have identified some socio-economic factors, for example, Kim, Park and Yoo, (2015) found that perceived levels of household income and education were the same, suicidal ideation increased as perceived social class decreased. The adjusted effect of the association between SES and perceived social class on suicidal ideation decreased according to the same pattern. Macassa, Olofsson, Soares, \& Ahmadi (2015) and Ha (2014) found that suicidal ideation was statistically significantly associated with SES as measured by education, occupation, and income and employment status. Controlling for demographic, socio-economic and health-related variables only eliminated the statistical significance for education and income. The study concluded that education, occupation, income and employment was associated with suicide ideation in Västernorrland County. Similarly, Hamilton, and Sampasa-Kanyinga (2016) in their study investigated the moderating role of subjective socio-economic status and parental education on the relationships between school connectedness and psychological distress, suicidal ideation and suicide attempts and found that higher subjective socio-economic status is associated with high levels of school connectedness. Subjective socio-economic status is also a significant moderator of the association between school connectedness and psychological distress, but not between school connectedness and suicidal ideation or attempts. At low subjective SES, there was no difference in risk of psychological distress between students with high and low levels of school compatibility. However, at higher subjective SES, students with high levels of school relatedness 
had lower odds of psychological distress than those with low levels of school relatedness. The relationship between school connectedness and each of the mental health outcomes did not significantly vary with parental education. In the same vein, Kim, Kim, Choi, Lee, and Park (2016) investigated associations with socio-economic status and suicidal ideation and found that low education and unemployed young adult men and women had significantly higher rates of attempts. The lowest income level was related with significantly higher rates of attempts in only young adult women. Among those with the lowest and highest income, the relationship between ideation and attempts was attenuated, whereas it was enhanced among other income groups.

\section{Theoretical Framework}

This study was based on the transactional model of stress which assert the transaction or interaction between the individual and his environment (Lazarus \& Folkman, 1984). According to this model, human perceptions and interpretations of events around humans determine their psychological or emotional impact. Selye (1956) who theorized that the body goes through several stages in response to sustained stress. The researcher proposed a three-step model called the general adaption syndrome (GAS) describing the reaction of the body to a stressor. The phase of this model include the alarm reaction, resistance, and exhaustion. The key to this model is that the body pays a price if it must constantly adapt to stress (Ray, 2004). The fight or flight model of stress(Cannon,1929) suggested that physiological changes that result from the activation of the autonomic nervous system and the endocrine system prepare an individual for an emergency reaction to either confront or fight the stressor or to fly away and escape from it.

Secondly, the social integration and social regulation theory by Durkheim (1991) states that there is an inverse relationship between suicidal ideation or behaviour and the degree of integration an individual has with his or her social group. This theory proposes that suicide results are, due to failure of social integration. The theory also posits that an individual will not die by suicide unless he/she has both the desire to die by suicide and the ability to do so. In the same vein, social integration and social regulation theory (Johnson, 1995) opined that the weakly integrated human in a solid social structure or the individual engulfed in a disorganized culture. The society with lessened or weak control facilitates the vulnerability of suicide. If the group control other hand, is too much, suicide may also result. The theory maintained that suicide ideation increases when once there is some dissonance or upset with respect to the relationship between the individual and the society. Hirschi's theory of social bond (1999) enunciated the social bond theory, which states four elements in the social bond between the individual and the society. These include: attachment, commitment, involvement in conventional activities. Hirschi (1999) found that high school students who felt close to their parents were less likely to engage in suicidal acts than their counterparts. Also, students who enjoyed and were successful in school were less likely to engage in suicidal ideation. Empirical reviews on previous studies as they relate to personality trait, perceived academic stress and socio-economic status on suicidal ideation among undergraduates were discussed.

\section{Statement of the Problem}

Empirical evidences have confirmed that there is high stress and suicidal ideation among undergraduates in tertiary institutions. Given that there is dearth of empirical studies that investigated the relationship between personality factors, perceived academic stress and socio-economic status among Nigerian undergraduates, there is need to investigate how personality factors, perceived academic stress and socio-economic status is related to suicidal ideation among undergraduates. However, there are inconsistencies in the findings obtained by previous researchers on the relationship between personality factors, perceived academic stress and socio-economic status among undergraduates indicates that research into the impact of those variables on suicidal ideation is not conclusive. More so, negative consequences of academic stress and socio-economic status on suicidal ideation among undergraduates calls for further research in order to increase our understanding on how to stem the tide of increasing academic stress and suicidal ideation among undergraduates. The main purpose of this study was to investigate the relationship among personality factors, perceived academic stress and socio-economic status on suicidal ideation among a previously unstudied sample of the population, Ebonyi state university undergraduates, Abakaliki, Nigeria.

\section{Hypotheses}

Based on the review of related literature, the following hypotheses were postulated and tested.

i. Personality factors will statistically significantly predict suicide ideation among undergraduates in Ebonyi State University.

ii. Perceived academic stress will statistically significantly predict suicide ideation among undergraduates in Ebonyi State University. 
iii. Socio-economic status will jointly and significantly predict suicide ideation among undergraduates in Ebonyi State University.

\section{Method}

\subsection{Participants}

The participants comprised 2500 undergraduates randomly selected from Ebonyi State Universities, Abakaliki, Nigeria. The gender spread of the participants were made up of 1058 males and 1442 females respectively. Sample age range were between 19 to 30 years with mean age 23,20 years. The total or overall sample of 2500 participants were drawn from different campuses of the university ;(a) Faculties of Biological Sciences (340), (b) Physical Sciences (202) (c) Education (706) (d) Law (246) (e) Agricultural Science (418) (f) Social Sciences and Humanities (308) (g) Management Sciences (280). In the same vein, 28\% of the participants were drawn from section of Education, $16.6 \%$ of the participants were from the section of Agricultural science, while $14.3 \%$ of the participants were from the section of Science.

\subsection{Measures}

Personality Trait Scale. It is a 44-item questionnaire developed by John, Donahue and Kentle, 1991 and revalidated by Omoluabi (2002) for Nigerian sample to assess the domain of personality trait (Neuroticism (N), Extroversion (E), Openness(O), Agreeableness(A), and Consciousness(C). The item response adopted a 5-point Likert scale ranging from strongly agree (1) to strongly disagree (5). The sample item includes; (1). Is a talkative. (2). Tends to find fault with others. (3). Does a thorough job. (4). is depressed, blue. (5). is original, comes up with new ideas. The co-efficient of internal consistency (Cronbach's alpha) of the scale ranged from 0.69 to 0.81.The instrument had previously been used in research with Nigerian sample (e.g., Udeagha, 2000) reported Cronbach's alpha Coefficients of $0.85,0.76,0.72,0.67$, and 0.80 respectively for the $\mathrm{N}, \mathrm{E}, \mathrm{O}, \mathrm{A}$, and $\mathrm{C}$ scales. For the present study, the Cronbach's alpha coefficients ranged from 0.70 to 0.87 . The coefficient of internal consistency of the items ranged between 0.71 to 0.86 for the N, E, O, A and C scales.

Perceived Academic Stress. This is a psychological questionnaire used by Cohen, Kamarck \& Mermelstein, (1983) and adopted for use in a Nigerian participants by Omoluabi (2000). The questionnaire contains 14 items designed to measure academic stress of undergraduates. It is scored on a 5-point Likert item between 4 (very often) to 0 (never), with total scores between 0-56; after reverse-scoring of 7 scales, higher mark showed higher perceived academic stress. Sample items on the scale include, "In the last month, how often have you dealt successfully with irritating life hassles?" The items had internal consistency of .85 and good test-retest reliability of .85 over two days with undergraduate student as participants

Suicidal Ideation Scale. This is a psychological questionnaire used by Beck \& Robert (1991). The questionnaire comprises 21-items used to measure suicidal ideation among undergraduate student participants. Both normal and abnormal undergraduate students sample can make use of suicidal ideation. It is recorded on a 3-point Likert scale between from 2 to 0 . The minimum score is 0 , while the maximum score is 42 . The scale had internal consistency of .87 and. 98. Since the scale was standardized using western sample to determine its Cronbach alpha), the need arose for the researcher to re-validate the instrument for the purpose of the present research.

\subsection{Procedure}

The survey forms containing all the three scales (big five personality inventory, perceived academic stress and suicidal ideation), and the demographic questions were administered to the randomly selected undergraduate students in the university that voluntarily participated in the study. Five research assistants comprising two undergraduate and three postgraduate students, who had been provided with ethical observances regarding the administered protocol, administered the survey scale. The undergraduates completed the survey forms anonymously and the purpose of the study of the research was explained to the participants. The participants were assured that their responses were confidential and would be treated as such.

\subsection{Design/Statistics}

This study adopted a cross-sectional survey research design that made use of four scales to collect data from the participants. Data colated were analysed using hierarchical multiple regressions analysis with the aid of statistical package for social sciences (SPSS: version 20).

\section{Results}

The descriptive statistics computed indicated that neuroticism reported higher mean score on suicide ideation $(M=48.53)$, followed by Openness to Experience $(M=19.26)$ on suicide ideation, whereas those of extraversion, agreeableness and conscientiousness reported negative prediction on suicide ideation and yielded $(M=8.45$; 
$\mathrm{M}=5.08 ; \mathrm{M}=4.45$, respectively). The output of the analyses also indicated that participants with perceived academic stress reported higher mean score $(\mathrm{M}=38.41)$. The results further indicated that participants socio-economic status recorded high mean score on suicide ideation $(\mathrm{M}=32.64)$. Test of significance of the means has been reported in Table 2 below.

Table 1. The Descriptive Statistics for the Variable under Study

\begin{tabular}{ccc}
\hline Variables & M & SD \\
\hline Suicide Ideation & 30.24 & 8.18 \\
Personality trait: & 48.53 & 6.10 \\
Neuroticism & 8.45 & 1.42 \\
Extraversion & 19.26 & 8.21 \\
Openness to Experience & 5.08 & 1.41 \\
Agreeableness & 4.45 & 2.04 \\
Conscientiousness & 38.41 & 4.12 \\
Academic Stress & 32.64 & 3.60 \\
Socioeconomic Status &
\end{tabular}

Note: $\mathrm{N}=2500, \mathrm{M}=$ Mean, $\mathrm{SD}=$ Standard Deviation

Table 2. The Hierarchical Multiple Regression Analysis for Prediction of Suicide Ideation through Personality Trait and Perceived Academic Stress and Socio-economic Status among Undergraduates

\begin{tabular}{|c|c|c|c|c|c|c|c|c|c|c|}
\hline Variables & Mean & SD & 1 & 2 & 3 & 4 & 5 & 6 & 7 & 8 \\
\hline 1 Suicide Ideation & 30.24 & 8.18 & - & & & & & & & \\
\hline 2 Neuroticism & 48.53 & 6.10 & $.38 * *$ & - & & & & & & \\
\hline 3 Extraversion & 8.45 & 1.42 & .23 & -.18 & _ & & & & & \\
\hline 4 Openness & 19.26 & 8.21 & $.26^{* *}$ & $.15^{*}$ & .10 & - & & & & \\
\hline 5. Agreeableness & 5.08 & 1.41 & .12 & .80 & $19^{*}$ & .11 & - & & & \\
\hline 6. Conscientiousness & 4.45 & 2.04 & .15 & -.24 & .06 & .18 & .13 & - & & \\
\hline 7. Academic Stress & 38.41 & 4.12 & $.35 * *$ & $-21^{*}$ & .05 & .02 & .14 & .19 & - & \\
\hline 8. Socio-economic St. & 32.64 & 3.60 & $.32 * *$ & $.20^{*}$ & .25 & $.19^{*}$ & .17 & $-13^{*}$ & $23^{*}$ & - \\
\hline
\end{tabular}

The results of hierarchical multiple regression analysis revealed that personality variables and neuroticism were positively correlated with suicidal ideation $(\mathrm{r}=.38, \mathrm{p}<.01)$. Extraversion showed no prediction with suicidal ideation $(\mathrm{r}=.23, \mathrm{p}<.05)$, Openness was positively significantly correlated with suicidal ideation $(\mathrm{r}=.26, \mathrm{p}<.01)$. Agreeableness and Conscientiousness showed no significant prediction on suicidal ideation among undergraduates. Results also indicated that perceived academic stress significantly correlated with suicidal ideation $(\mathrm{r}=.35, \mathrm{p}<.01)$. Results further revealed that socio-economic factors positively correlated with suicidal ideation among undergraduates.

\section{Discussions}

The purpose of this study aimed specifically to investigate the prediction of suicide ideation through personality trait, perceived academic stress and socioeconomic status among undergraduates of Ebonyi state University, Abakaliki. The hypothesized, personality factors were associated with suicide ideation among undergraduates. The results found that two of the personality factors, neuroticism and openness to experience were associated with suicide ideation. The result were in line with the findings of previous researchers, who reported that suicidal ideation was predicted by neuroticism and openness to experience (Heisel, Beckman, Conner, Duberstein, \& Franus, 2006; Chioqueta \& Stiles, 2005; McLean, Maxwell, Platt, Harris, \& Jepson, 2008). These findings could be attributed to the fact that undergraduates with high scores in agreeableness, conscientiousness and extraversion frequently working harder, put more determinations and commitment to their studies and achieved more in their academic work even at the cost of their well-being.

As hypothesized in this study, the result revealed that perceived academic stress had significant correlation with suicidal ideation. These results vindicated the findings of previous researchers who reported that undergraduates who possessed higher levels of academic stress were high in suicidal ideation (Johnson, Gooding, Wood, \& Tarrier, 2010). The results from this study also supported the work of Anastasiades, Kapoor and Wooten (2016) 
who found that mindfulness moderated the mediated effect of depressive symptoms on perceived stress and suicidal ideation. Also, Farhad, Abbas, Khaled and Hanieh (2013) found that positive association between perceived academic stresses with suicide ideation. Also, results indicated that emotion- oriented strategies with perceived academic stress and emotion- oriented strategies with suicide ideation were related. Similary, Ibrahim, Amit and Suen (2014) found significant relationship between perceived academic stress, anxiety, and depression with suicidal ideation. In the same vein, Esther (2015) found that depressive symptoms partially mediate the association between perceived academic stress and suicidal acts, such that greater academic stress was associated to depression and, in turn, to greater participation in suicidal acts. Clarification for this result is that there are certain issues among the undergraduates' perceived academic stress that cause them more suicidal ideation. Examples of issues in the undergraduate's perceived academic stress that served as sources of stress included relating to other people, academic factors, personal factors, environments factors. Perceived academic stress arises when an undergraduates assesses the environment as one that tasks or outstrips his/ her resources and therefore is perceived as threatening. Undergraduates who have high prospects and want to accomplish may be prone to stress and suicidal ideation (Wichianson, Bughi, Unger, Spruijt-Metz, \& Nguyen-Rodriguez, 2009)

As expected, socio-economic status played a significant role in predicting suicidal ideation among undergraduates. This finding is consistent with those of previous researchers who reported similar results (Kim, Park \& Yoo, 2015; Macassa, Olofsson, Soares, \& Ahmadi, 2015; Ha, 2014). In the vein, Kim, Kim, Choi, Lee, and Park (2016) investigated associations with socio-economic status and suicidal ideation and found that low education and unemployed young adult men and women had significantly higher rates of attempts. The lowest income level was associated with significantly higher rates of attempts in only young adult women. Likely clarification for these results could be that when undergraduates face socio-economic status difficulty from their parents, brothers, relatives, friends, and others, it would increase the rate of suicidal ideation.

\section{Implications of the Findings}

These results have important implications for the prevention of suicidal ideation, suggesting that suicide prevention programs, counseling centers, and psychological clinics on university campuses should include suicide attitudes as well as depression, hopelessness, and perceived stress in their assessment and identification of individuals who may be at risk for engaging in suicide ideation. Also, the study has very significant implications in educational and organizational sectors of our society today. This study has aided the researcher to understand the negative aspects of personality factors, perceived academic stress and socio-economic status as they predispose individuals to suicidal ideation among undergraduates. Also, this study will be useful for the school managements and organizations on how to screen their students during admission and during recruitment exercises as a way of nipping the issue of suicide ideation in the bud.

This study is a cross sectional survey design and used questionnaire for data collection, which made the researcher not to investigate causality or directionality of the factors of investigation on suicide ideation. These are obvious limitations. In addition to the use of questionnaire, interview and focused group discussions could be used to complement the data collection instrument. Another limitation lies in the sample as only the undergraduate students of the Ebonyi State University were sampled without comparison with other universities in Nigerian settings. Despite these constraints, the present study has contributed to the body of knowledge of literature on personality factors, perceived academic stress and socio-economic status and suicidal ideation among undergraduates.

\section{References}

Agolla, J. E., \& Ongori, H. (2009). An assessment of academic stress among undergraduate students: The case of university of Botswana. Educational Research and Review, 4(2), 63-70.

Alloy, B., Jacobson, N. S., \& Acocella, J. (1999). Abnormal psychology. Boston; McGraw-Hill Companies.

American Psychological Association. (2004, March, 2nd). Suicide prevention and youth: Saving Lives. Retrieved from http://www.apa.org/ppo/king.html

Anastasiades, M. H., Kapoor, S., \& Wooten, J. (2016). Perceived stress, depressive symptoms, and suicidal ideation in undergraduate women with varying levels of mindfulness. Archive Women Mental Health, 9(8), 78-98. https://doi.org/10.1007/s00737-016-0686-5

Ang, R. P., \& Huan, V. S. (2006). Relationship between academic stress and suicidal ideation: Testing for depression as a mediator using multiple regression. Child Psychiatry and Human Development, 37(2), 133-143. https://doi.org/10.1007/S10578-006-0023-8

Ashouri A., \& Asgarabad, H.M. (2009). Examined relationship between suicidal ideation and personality in 
substance abusers. Journal of Behavioral Sciences, 3(3), 249-255. https://doi.org/10.5812/ircmj.12686

Block, J. (1995). Going beyond the five factors given: Rejoiner to Costa and McCrae (1995) and Goldberg and Saucier (1995). Psychological Bulletin, 117, 226-229. https://doi.org/10.1007/978-1-4615-0763-5_2

Brezo, J., Paris, J., \& Turecki, G. (2006b). Personality traits as correlates of suicidal ideation, suicide attempts, and suicide completions. A Systematic Review Acta Psychiatric Scandinavian, 113, 180-206. https://doi.org/10.1111/j.1600-0447.2005.00702.x

Brown, L. K. (2011). Predictors of suicide ideation and the moderating effects of suicide attitudes. Theses and Dissertations, 540. The University of Toledo Digital Repository.

Brown, C., \& O'Brien, K. M. (1998). Understanding stress and burnout in shelter workers. Professional Psychology: Research and Practice, 29(4), 383-385.

Busari, C., \& Uwakwe T. (2001).The effect of stress inoculation training technique in the management of worry as a self-handicapping strategy in intellectual performance. Nigerian Journal of Emotional Psychology, 3, 6-12.

Busari, A. O. (2000). Stress inoculation training and self-statements monitoring techniques on the reduction of test anxiety among adolescent Underachievers in Ibadan Metropolis. International Journal of Humanities and Social Science, 2(14), 146-154.

Busari, A. O. (2011). Stress inoculation techniques in fostering adjustment to academic stress among undergraduate Students. British Journal of Humanities and Social Sciences, 2(1), 229-243.

Busari, A. O. (2011). Validation of student academic stress scale (SASS). European Journal of Social Sciences, 21(1), 94-105.

Busari, A. O. (2012). Identifying difference in perceptions of academic stress and reaction to stressors based on gender among first year university students. International Journal of Humanities and Social Science, 2(14), $138-146$.

Cannon, W. B. (1929). Bodily change in pain, hunger, fear and rage (2nd ed). New York: Appleton-Century-Crafts.

Carson, R. C., Butcher, J. N., \& Mineka, S. (1998). Abnormal Psychology and Modern Life. New York; Longman.

Cheng, K. W. (2009). A study of stress sources among college students in Taiwan. Journal of Academic and Business Ethics, 2, 1-8.

Chioqueta, A. P., \& Stiles, T. C. (2005). Personality traits and the development of depression, hopelessness, and suicide ideation. Personality and Individual Differences, 38(6), 1283-1291. http://dx.doi.org/10.1016/j.paid.2004.08.010

Coffey, M. (1999). Stress and burnout in forensic community mental health nurses: an investigation of its causes and effects. Journal of Psychiatric and Mental Health Nursing, 6, 433-443. https://doi.org/10.1046/j.1365-2850.1999.00243.x

Conner, J., Pope, D., \& Galloway, M. (2010). Success with less stress. Health and Learning, 67(4), 54-58.

Costa, P. T., \& McCrae, R. R. (1985). The NEO personality inventory manual, Odessa, FL: psychological assessment resources. Annual Psychological Bulletin, 8, 140-168. https://doi.org/10.1177/1073191104265800

Cox, B. J., Enns, M. W., \& Clara, I. P. (2004). Psychological dimensions associated with suicidal ideation and attempts in the national comorbidity survey. Suicide and Life-Threatening Behavior, 34(3), 209-220.

Daniel, L. S., Meghan, A. M., William, J. M., \& Frederick, L. C. (2012). Personality, suicidal ideation, and reasons for living among older adults. The Journals of Gerontology, Series B: Psychological Sciences and Social Sciences, 67(2), 159-166. https://doi.org/10.1093/geronb/gbr080

DeShong, H. L, Tucker, R.P., O'Keefe, V. M., Mullins-Sweatt, S.N. \& Wingate L. R. (2015). Five factor model traits as a predictor of suicide ideation and interpersonal suicide risk in a college sample. Psychiatry Research, 1-7. https://doi.org/10.1016/j.psychres.2015.01.002.

Dogra, A. K., Basu, S., \& Das, S. (2008). The roles of personality, stressful life events, meaning in life, reasons for living on suicidal ideation: A study in college students. Journal of Projective Psychology \& Mental Health, 15, 52-57. 
Duberstein, P. R., Conwell, Y., Seidlitz, L., Denning, D. G., Cox, C., \& Caine, E. D. (2000). Personality traits and suicidal behavior and ideation in depressed inpatients 50 years of age and older. Journal of Gerontology: Psychological Sciences, 55B(1), 118-126.

Edlin, G., \& Golanty, E. (1995). Health and wellness: A holistic approach. Boston: Jones and Bartlett Publishers, Inc.

Esther, E. R. (2015). Perceived stress and suicidal behaviors in college students: Conditional indirect effects of depressive symptoms and mental health stigma. A thesis presented to the faculty of the Department of Psychology East Tennessee State University.

Eun-Jun, B. (2009). The Effects of Gender, Academic Concerns, and Social Support on Stress for International Students (Unpublished $\mathrm{PhD}$ thesis). University of Missouri-Columbia.

Fanous, A. H., Prescott C. A, \& Kendler, K. S. (2004). The prediction of thoughts of death or self-harm in a population-based sample of female twins. Psychological Medicine, 34, 301-312. https://doi.org/10.1017/S0033291703008857

Farhad, A., Abbas, S., Khaled, A. S., \& Hanieh, K. (2013). Relationship between perceived stress, coping strategies and suicide ideation among students at university of Guilan, Iran. International Journal of Education and Research, 1(11), 1-8. https://doi.org/10.1080/0144341960160104

Gentry, L. A., Chung, J. J., Aung, N., Keller, S., Heinrich, K. M., \& Maddock, J. E. (2007). Gender differences in stress and coping among adults living in Hawai Californian. Journal of Health Promotion, 5(2), 89-102.

Gould, M. S., Greenberg, T., Velting, D., \& Shaffer, D. (2003). Youth suicide risk and preventive interventions: A review of the past 10 years. Journal of American Academic and Child Adolescent Psychiatry 42, 386-405.

Gutierrez, P. M., Osman, A., Kopper, B. A., \& Barrios, F. X. (2000). Why young people do not kill themselves: the Reasons for living inventory for adolescents. Journal of Clinical Child Psychology, 29, 177-187. https://doi.org/10.1207/S15374424jccp2902_4

Gutierrez, P. M., \& Osman, A. (2008). Adolescent suicide: An integrated approach to the assessment of risk and protective factors. DeKalb, IL: Northern Illinois University Press.

Ha, J.Y. (2014). Suicidal ideation, suicide plans and attempts in Korean adolescents. Healthcare and Nursing, 72, 117-122. https://doi.org/10.14257/astl.2014.72.29

Hamilton, H. A., \& Sampasa-Kanyinga, H. (2016). Does socioeconomic status moderate the relationships between school connectedness with psychological distress, suicidal ideation and attempts in adolescents? Preventive and Medicine, 87, 11-17. https://doi.org/10.1016/j.ypmed.2016.02.010

Heisel, M. J., Duberstein, P. R., Conner, K. R., Franus, N., \& Beckman, A. et al. (2006). Personality and reports of suicide ideation among depressed adults 50 years of age or older. Journal of Affect Disorder, 90, 175-180. https://doi.org/10.1016/j.jad.2005.11.005

Hintikka, J., Koivumaa-Honkanen, H., Lehto, S. M., Tolmunen, T., Honkalampi, K., Haatainen, K., \& Viinamaki, H. (2009). Are factors associated with suicidal ideation true risk factors? A 3 year prospective follow-up study in a general population. Social Psychiatry and Psychiatric Epidemiology, 44, 29-33. https://doi.org/10.1007/s00127-008-0401-6

Holdsworth, N., Belshaw, D., \& Murray, S. (2001). Developing A\&E nursing responses to people who deliberately self-harm: the provision and evaluation of a series of reflective workshops. Journal of psychiatric and mental health nursing, 8(5), 449-58.

Howland, R. H., \& Thase, M. E. (2005). Refractory and chronic depression: Role of axis II disorders in assessment and treatment. In M. Rosenbluth, S. H. Kennedy, \& R. M. Bagby (Eds.), Depression and Personality: Conceptual and Clinical Challenges. Washington, DC: American Psychiatric Publishing, Inc.

Humphrey, J. H., Yow, D. A., \& Bowden, W. W. (2000). Stress in College Athletes: Causes, Consequences, Coping. Binghamton, NY: The Haworth Half-Court Press. An imprint of the Haworth Press, Inc.

Hussain, A., Kumar, A., \& Husain, A. (2008). Academic stress and adjustment among high school students. Journal of the Indian Academy of Applied Psychology, 34, 70-73.

Hyman, M. R. \& Sierra, J. J. (2010). Marketing Research Kit for Dummies. Hoboken, NJ: Wiley Publishing Inc.

Ibrahim, N., Amit, N., \& Suen, M. W. Y. (2014). Psychological factors as predictors of suicidal ideation among adolescents in Malaysia. PLoS ONE, 9(10), 1-6. https://doi.org/10.1371/journal.pone.0110670. 
Ifeagwazi, C. M. (2016). Stress-Illness connection: Critical factors moderating the link. $109^{\text {th }}$ inaugural lecture of the University of Nigeria, Nsukka.

Ifeagwazi, C. M., Chukwuorji, J. C., \& Kalu, O. G. (2013). Role of stress reactivity, age and gender on neuroticism among students. International Journal of Research in Arts and Social Sciences, 5, 521-530.

Jogaratnam, G., \& Buchanan, P. (2004). Balancing the demands of school and work: Stress and employed hospitality students. International Journal of Contemporary Hospitality Management, 16(4), 237-245. https://doi.org/10.1108/09596110410537397

Johnson, M. (2009). Community college students' perception of stress. Journal of Biology of Exercise, 5(1), 15-28. https://doi.org/10.4127/jbe.2009.0022

Kaplan, H. I., Sadock, B. J. \& Grebb, J. A. (1994). Kaplan and Sadock's Synopsis of Psychiatry: Behavioural Science's Clinical Psychiatry, 19(6), 56-78.

Kelsall, H. L., McKenzie, D. P., Forbes, A. B., Roberts, M. H., Urquhart, D. M., \& Sim, M. R. (2014). Pain-related musculoskeletal disorders, psychological comorbidity, and the relationship with physical and mental well-being in Gulf War veterans. Pain, 155(4), 685-692. https://doi.org/10.1016/j.pain.2013.12.025

Kerby, D. S. (2003). CART analysis with unit-weighted regression to predict suicidal ideation from big five traits. Personality and Individual Differences, 35(2), 249-261. https://doi.org/10.1016/S0191-8869(02)00174-5

Kim, J., Park, E., \& Yoo, K. (2015).Effects of the gap between socioeconomic status and perceived social class on suicidal ideation: Unique perspectives using a longitudinal analysis. Archives of Gerontology and Geriatrics, 61(3), 384-391. https://doi.org/10.1016/j.archger.2015.06.002

Kim, J. L., Kim, J. M., Choi, Y., Lee, T., \& Park, E. (2016). Effect of socioeconomic status on the linkage between suicidal ideation and suicide attempts. Suicide and Life-Threatening Behavior, 46(5), 588-596. https://doi.org/10.1111/sltb.12242.

Kumar, S., \& Jejurkar, K. (2005). Study of stress level in occupational therapy students during their academic curriculum. The Indian Journal of Occupational Therapy, 37(1), 5-14.

Larsen, R. J., \& Buss, D. M. (2005). Personality Psychology: Domains of Knowledge about Human Nature (2nd Ed.). New York: McGraw-Hill

Lazarus, R. S., \& Folkman S. (1984). Stress, Appraisal, Coping. New-York: Springer Publishing Company

Lee, S.I., \& Jung H (2006). Psychosocial risk factors for suicide. Psychiatry Invest, 3, 15-22. https://doi.org/10.1176/appi.ps.55.12.1414

Leong, C. S., Furnham, A., \& Cooper, C. L. (1996). The moderating effects of organizational commitment on the occupational stress outcome relationship. Human Relations, 49, 1345-1363. https://doi.org/10.1177/001872679604901004.

Levi-Belz, Y. (2014). Stress-related growth among suicide survivors: The role of interpersonal and cognitive factors. Journal Archives of Suicide Research, 19(3), 305-320. https://doi.org/10.1080/13811118.2014.957452

Macassa, G., Olofsson, N., Soares, J. J. F., \& Ahmadi, N. (2015). Socioeconomic position and suicidal ideation: going beyond education, occupation and income. Middle Sweden Journal of Public Health, 1(1)1-31. https://doi.org/10.13183/msjph.v1i1.150.

Masih, P. P., \& Gulrez, N. K. (2006). Age and Gender Differences on Stress. In A. Husain, \& M. I. Khan (Eds.). Recent Trends in Human Stress Management (pp. 97-104). New Delhi, India: Global Mission Publishing

Mason, J. W. (1975). A historical view of the stress field. Journal of Human Stress, 1, 22-36. https://doi.org/10.1080/0097840X.1975.9940399

Matud, M. P. (2004). Gender differences in stress and coping styles. Personality and Individual Differences, 37(7), 1401-1415. https://doi.org/10.1016/j.paid.2004.01.010

McCrae, R. R., \& Costa, P. T. (1999) A five-factor theory of personality. In L. A. Pervin, \& O. P. John (Eds.). Handbook of Personality: Theory and Research (2nd ed.). New York: The Guilford Press

Misra, R., \& Castillo, L. G. (2004). Academic stress among college students: Comparison of American and international students. International Journal of Stress Management, 11(2), 132-148. https://doi.org/10.1037/1072-5245.11.2.132 
Misra, R., \& McKean, M. (2000). College students' academic stress and its relation to their anxiety, time management, and leisure satisfaction. American Journal of Health Studies, 16(1), 41-51

Moore, K. A., \& Cooper, C. L. (1998). Theories of stress among mental Health professionals. In S. Hardy, J. Carson, \& B. Thomas (Eds.), Occupational stress: Personal and professional approaches. Cheltenham: Stanley Thrones.

Muiru, A., Thinguri, R., \& Macharia, S. (2014). An exploration of the influence of personality traits on suicide ideation and attempts in public secondary school students in Kenya. International Journal of Innovation and Scientific Research, 9(2), 448-455.

Murphy, K. R., \& Davidshofer, C. O. (2005). Psychological Testing (6th ed.). New Jersey: Pearson Prentice Hall.

Neale, J. M., \& Liebert, R. M. (1980). Science and Behavior: An Introduction to Methods of Research (2nd ed.). New Jersey: Prentice Hall Inc.

Nevid, J. S., Rathus, S. A., \& Green, B. (1994). Abnormal Psychology in a Changing World. New Jersey: Prentice Hall Inc.

Peirson, A. R. (2001). Personality and Suicide Ideation in Adolescents and Young Adults (Unpublished Mater's Dissertation). University of Witwatersrand.

Pervin, L. A., \& John O. P. (1997). Personality: Theories and Research (7th ed.). New York: John Wiley \& Sons.

Pienaar, J., Rothman, S., \& van der Vijver, J. R. (2007). Occupational stress, personality traits, coping strategies, and suicide ideation in the South African Police Service. Criminal Justice and Behavior, 34(2), 246-258. https://doi.org/10.1177/0093854806288708

Planas, M. G., Bennasar, M. R., Perez, V. F., \& Arroyo, M. B. (2001). Suicidal ideation, psychiatric disorder, and medical illness in a community epidemiological study. Suicide and Life-Threatening Behavior, 31(2), 207-213. https://doi.org/10.1521/suli.31.2.207.21508

Richlin-Klonsky, J., \& Hoe, R. (2003). Sources and Levels of Stress among UCLA Students. Student Affairs Briefing, 2.

Rohtash, S., \& Hardeep, L.J. (2008). Suicidal ideation in relation to depression, life stress and personality among college students. Journal of Indian Academic and Applied Psychology, 34, 259-265.

Rosiek, A., Rosiek-Kryszewska, A., Leksowski, L., \& LeksowskiK, K. (2015). Chronic stress and suicidal thinking among medical students. International Journal of Environmental Research and Public Health, 13(212), 2-6. https://doi.org/10.3390/ijerph13020212.

Schlebusch, L. (2005b). Suicidal behaviour in South Africa. Pietermaritzburg: University of KwaZulu-Natal Press

Selye, H. (1956). The Stress of Life. New York; McGraw-Hill Companies.

Seyyed, V. M., Negar, S., \& Sajjad, R. (2015). Role of the big five personality traits in chemical suicide attempt. Practice in clinical psychology, 3(4), 236-242.

Shafi, S., \& Touseef, T. (2015). A study of perceived stress, suicidal ideation and religiosity among young adults. The International Journal of Indian Psychology, 3(1), 1-20.

Shah, M., Hasan, S., Malik, S., \& Sreeramareddy, C. T. (2010). Perceived stress, sources and severity of stress among medical undergraduates in a Pakistani Medical School. BMC Medical Education, 10(2), 1-8. https://doi.org/10.1186/1472-6920-10-2.

Shaikh, B. T., Kahloon, A., Kazmi, M., Khalid, H., Nawaz, K., Khan, K. A., \& Khan, S. (2004). Students, stress and coping strategies: A case of Pakistani Medical School. Education for Health, 17(3), 346-353. https://doi.org/10.1080/13576280400002585

Salami, S. O. (2011) Job stress and burnout among lecturers: personality and social support as moderators. Asian Social Science, 7(5), 110-121. https://doi.org/10.5539/ass.v7n5p110

Singh, R., \& Joshi, H. L. (2008). Suicidal ideation in relation to depression, life stress and personality among college students. Journal of the Indian Academy of Applied Psychology, 34, 259-265.

Smith, B. L. (2014). Psychologists need more training in suicide risk assessment. Monitor on Psychology, 45, $42-42$.

Smith, J. M., Alloy, L. B., \& Abramson, L. Y. (2006). Cognitive vulnerability to depression, rumination, 
hopelessness, and suicidal ideation: Multiple pathways to self-injurious thinking. Suicide and Life-Threatening Behavior, 36, 443-454. https://doi.org/10.1521/suli.2006.36.4.443.

Soltaninejad, A., Fathi-Astiani, A., Ahamdi, A., Mirsharafoddini, H. S., Nikmorad, A. \& Pilevarzadeh, M. (2014). Personality factors underlying suicidal behavior among military youth. Iranian Red Crescent Medical of Journal, 16(4), 34-56. https://doi.org/10.5812/ircmj.12686

Stephenson, H., Pena-Shaff, J., \& Quirk, P. (2006). Predictors of college student suicidal ideation: Gender differences. College Student Journal, 40, 109-117.

Sulaiman, T., Hassan, A., Sapian, V. M., \& Abdullah, S. K. (2009). The level of stress among students in urban and rural secondary schools in Malaysia. European Journal of Social Sciences, 10(2), 179-184. http://psasir.upm.edu.my/id/eprint/17239

Taylor, N. (2004). The Construction of a South African Five-Factor Personality Questionnaire. Unpublished Master Dissertation, Rand Afrikaans University, South Africa.

Taylor, S. E. (2003). Health Psychology. Boston; McGraw-Hill Companies.

Tsai, S.L. (1997). The development of a nurse stress checklist from English to Chinese version. Issues in Mental Health Nursing, 18(3), 247-57.

Tsai, S. L., \& Crockett, M. S. (1993). Effects of relaxation training, combining imagery, and meditation on the stress-level of Chinese nurses working in modern hospitals in Taiwan. Issues in Mental Health Nursing, 14(1), 51-66. https://doi.org/10.3109/01612849309006890

Tyssen, R., Vaglum, P., Gronvold, N. T., \& Ekeberg, O. (2000). The impact of job stress and working conditions on mental health problems among junior house officers. Medical Education, 34, 374-384. https://doi.org/10.1046/j.1365-2923.2000.00540.x

Tyssen, R., Vaglum, P., Gronvold, N. T., \& Ekeberg, O. (2001). Suicidal ideation among medical students and young physicians: a nationwide and prospective study of prevalence and predictors. Journal of Affective Disorders, 64(1), 69-79. https://doi.org/10.1016/S0165-0327(00)00205-6

Useda, J. D, Duberstein, P. R., Conner, K. R., \&Conwell, Y. (2004). Personality and attempted suicide in depressed adults 50 years of age and older: A facet level analysis. Comprehensive Psychiatry, 45, 353-361. https://doi.org/10.1016/j.comppsych.2004.06.002

Velting, D. M. (1999a). Suicidal ideation and the five-factor model of personality. American Psychologist, 16(14), 789-899. https://doi.org/10.1016/S0191-8869(99)00046-X

Victor, B., Nestor, D. K., Stephan, D., Elmar, B., Birgit, W., \& Anette, K. (2013). Personality factors and suicide risk in a representative sample of the German general population. PLoS ONE, 8(10), 1-7. https://doi.org/10.1371/journal.pone.0076646.

Watson, R. L. (2002). A comparison of perceived stress levels and coping styles of junior and senior students in nursing and social work programs (Unpublished $\mathrm{PhD}$ thesis). Marshall University.

Wichianson, J. R., Bughi, S. A., Unger, J. B., Spruijt-Metz, D., \& Nguyen-Rodriguez, S. T. (2009). Perceived stress, coping and night-eating in college students. Journal of the International Society for the Investigation of Stress, 25, 235-240. https://doi.org/10.1002/smi.1242.

Wilks, S. E. (2008). Resilience and academic stress: The moderating impact of social support among social work students. Advances in Social Work, 9(2), 106-125.

Wood, S. E., Wood, E. G., \& Boyd, D. (2008). The World of Psychology. Boston: Pearson Education Inc.

Younge, J. O., Wester, V. L., Van Rossum, E. F. C., Gotink, R. A., Wery, M. F., Utens, A. E. M. W. J., \& Roos-Hesselink, J. W. (2015). Cortisol levels in scalp hair of patients with structural heart disease. International Journal of Cardiology, 184, 71-78. https://doi.org/10.1016/j.ijcard.2015.02.005

\section{Copyrights}

Copyright for this article is retained by the author(s), with first publication rights granted to the journal.

This is an open-access article distributed under the terms and conditions of the Creative Commons Attribution license (http://creativecommons.org/licenses/by/4.0/). 